\title{
41. Note on a Subcutaneously Transplanted Mouse Testis with Spermatogenetic Activity.
}

\author{
By Kiyoshi TakewakI.
}

Zoological Institute, Faculty of Science, Tokyo Imperial University.

(Comm. by N. YATSU, M.I.A., April 12, 1938.)

It is well known that in rats and guinea pigs testis grafts subcutaneously, peritoneally or intramuscularly implanted fail to produce spermatozoa. But in testis transplanted to the tunica vaginalis in the scrotum mature spermatozoa may be produced (Moore, 1926 ${ }^{1)}$; Browman, 19372). From the results of his extensive studies upon cryptorchid testis and testis graft, Moore concluded that temperature regulation is necessary for the spermatogenetic function of the testis and emphasized the scrotum as a thermo-regulator necessary for the production of spermatozoa.

In mice, however, I have already shown that the influence of abdominal retention upon the testis is not so great as in rats and guinea pigs and in the cryptorchid testis the spermatogenesis may go on or the spermatogenetic function may be regained after the temporary degeneration of the germinal epithelium and mature spermatozoa may be produced (Takewaki, 1934). ${ }^{3)}$ From this it has being expected that in mice non-scrotal testis graft can also produce spermatozoa. Here I shall report a case of mouse testis subcutaneously grafted in which a good many spermatozoa were found.

In a 28-day-old male mouse immediately after castration transplantation of a testis from a litter-brother was made on Sept. 21, 1937.
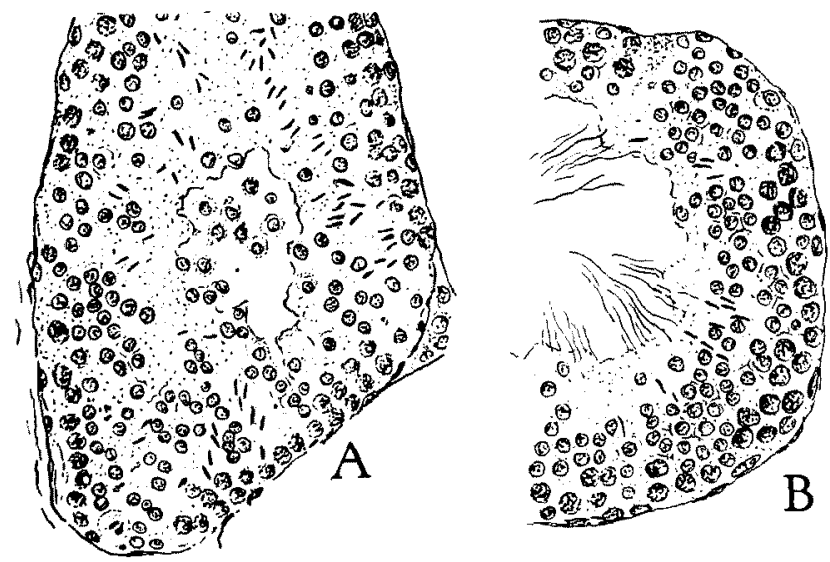

Fig. 1. Sections of two seminiferous tubules of testis graft. A Germinal epithelium is somewhat deranged and spermatozoa are still young. B Germinal epithelium is almost normal with mature spermatozoa $\times 250$

1) Moore, C. R. 1926 Am. J. Anat., vol. 37, pp. 351-416; Am. Naturalist, vol. 60, pp. $324-333$.

2) Browman, L. G. 1937 J. Exp. Zool., vol. 75, pp. 283-311.

3) Takewaki, K. 1934 J. Fac. Sci., Imp. Univ. Tokyo, Sec. IV, vol. 3, pp. 319-323. 
The graft was taken out and fixed on Dec. 20, i.e., 90 days after transplantation. The testicular tissues were well preserved. A few seminiferous tubules were highly degenerated having lost all the germ cells save a few spermatogonia and the Sertoli cells. The majority of the tubules, however, retained the spermatogenetic function and contained spermatocytes and spermatids but no spermatozoa. But in approximately twenty per cent of the tubules were found spermatozoa. Most of the spermatozoa were still young, yet they appeared quite normal (fig. 1). The graft had been removed from the donor earlier than spermatozoon formation, hence it is clear that the spermatozoa were really produced after transplantation. It should be added here, however, that only one of twenty-three grafts so far studied contained spermatozoa. Browman (1937) $)^{1}$ made four testis autografts sutured to the tunica vaginalis in the scrotum of mice and found spermatozoa in all the grafts when examined a few months after transplantation. In mice also the scrotum seems to provide to testis a better environment than other parts of the body for carrying spermatogenesis to completion. The interstitial cells in the graft were also well developed.

The accessories, especially the seminal vesicles and preputial glands in the animal were normal struct ${ }^{+}$rrally as well as in development. It should be concluded, therefore, that the graft was also active in its hormonic production.

1) $l . c$. 